\title{
3D Body Databases of the Spanish Population and its Application to the Apparel Industry
}

\author{
Alfredo BALLESTER*, Marta VALERO, Beatriz NACHER, Ana PIEROLA, Paola PIQUERAS, \\ María SANCHO, Gloria GARGALLO, Juan C. GONZALEZ, Sandra ALEMANY \\ Instituto de Biomecánica de Valencia, Universidad Politécnica de Valencia, Valencia, Spain
}

DOI: 10.15221/15.232 http://dx.doi.org/10.15221/15.232

Keywords: 3D, anthropometry, body, male, female, children, size table, measurement, database, avatar, mannequin, scanning, shape, data-driven, PCA, statistical, clothing, apparel, EN 13402 labelling,intervals

\begin{abstract}
Since the conduction of the CAESAR survey in the year 2000, more than 20 large-scale national or specific population surveys have been conducted across the world using $3 \mathrm{D}$ body scanning technologies of different kind. These surveys have been mainly addressed to the apparel industry and for some cases also for healthcare applications, most of the studies have been based on the use of a set of body measurements typically following ISO 8559 and ISO 7250 definitions.
\end{abstract}

In Spain, IBV conducted the Spanish female survey in 2007-2008 and has recently completed the male (2013-2014) and children surveys (2014-2015). The whole Spanish 3D database comprises over 12.000 individuals in standing posture sharing a common homologous structure and includes over 50 measurements by individual.

The recent standard EN 13402-3:2013 proposes to substitute the size codes of garment (e.g. XS, S, $\mathrm{M}, \mathrm{L}, \mathrm{XL}$, etc. or $36,38,40,42,44$, etc.) by the use of the body measurements that would fit the person wearing that garment. This document, currently under review, proposes the use of a pair of body measurements (i.e. one primary and one secondary) for the size designation and labelling of each type of garment (e.g. hips-waist for trousers, chest-neck for shirts, bust-hips for dresses, etc.). It also determines, for each primary and secondary pair of measurements, the intervals to be used for compiling standard garment sizes for men, women, boys, girls and infants based on the national anthropometric studies of different European countries (i.e. Netherlands, France, Sweden, Germany, Romania and Spain).

This paper describes the main results of the three Spanish surveys. And it also presents series of tools that will help the apparel manufacturers and retailers to make an effective use of Spanish databases in the design and labelling of products addressed to the Spanish market following the forthcoming size designation interval standards (EN 13402). These tools consist of a website providing with the basic anthropometric statistics, two books with the population measures by age range (one for female and one for male populations), a collection of digital mannequins and a collection of physical mini-mannequins (scale 1/20). Moreover, the access to the 3D databases makes possible to IBV to extend the use of these data for the provision of new consultancy services for clothing companies about how to improve garment design and fitting.

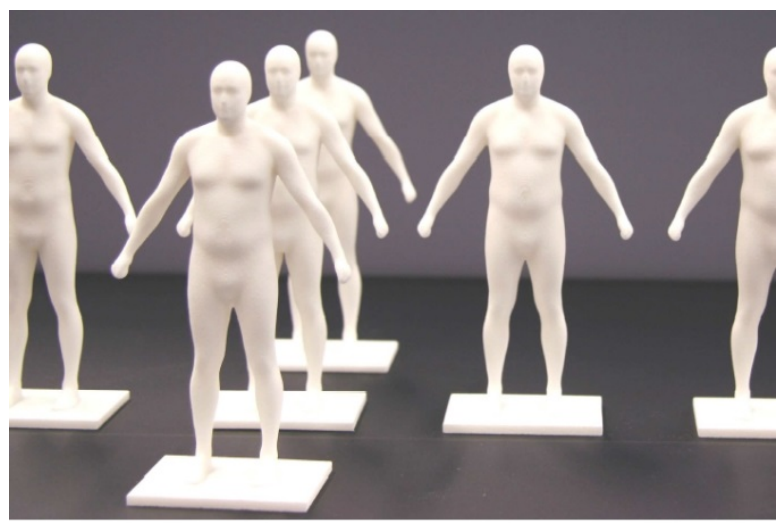

Fig. 1: Examples of mini-mannequins of the Spanish male population

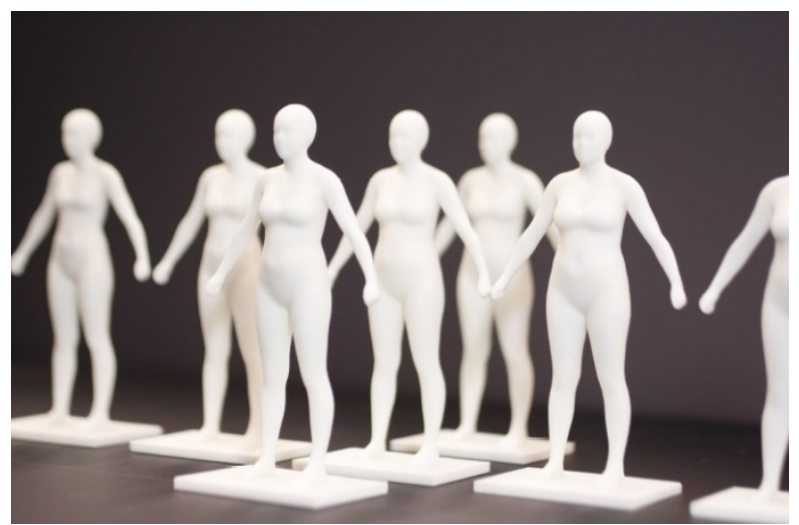

Fig. 2: Examples of mini-mannequins of the Spanish female population

* corresponding author alfredo.ballester@ibv.upv.es 


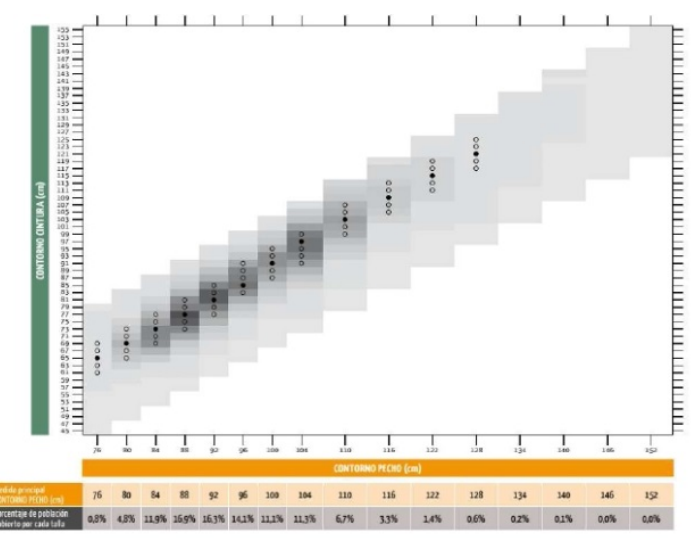

Fig. 1: Example of application of ISO/DIS 8559-2 to Spanish female population (Waist vs. Hips)

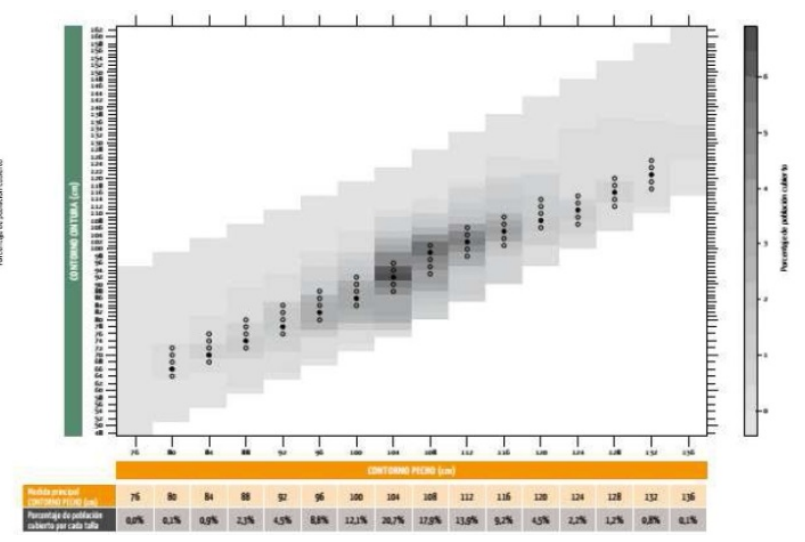

Fig. 2: Example of application of ISO/DIS 8559-2 to Spanish population (Waist vs. Chest) 